\title{
Effectiveness of lightning pheromone application against mulberry Glyphodes pylaialis $W$.
}

\author{
Z. Nosirova ${ }^{1, *}$ and $M$. Tojieva ${ }^{1}$ \\ ${ }^{1}$ Tashkent State Agrarian University, University str., 2, Tashkent province, Uzbekistan, 100140
}

\begin{abstract}
An analysis of the results of experiments to determine the effectiveness of the use of illuminated pheromone catchers in the fight against mulberry moth was presented. The experiments used pheromone handles impregnated with antioxidant pheromone material and placed on a lamp based on 2 light-emitting diodes operating in the ultraviolet radiation range of $365-370 \mathrm{~nm}$. According to the analysis of the results, it was observed that mulberry moths caught on illuminated pheromone traps were 2.15 times more than non-illuminated catches, and the number of moths caught at night was about 1.75 times higher than the number of moths caught daytime.
\end{abstract}

\section{Inroduction}

It is known that pheromone traps play a role in pest control activities. The main reasons for this can be explained by the fact that this method is completely harmless to the environment, water, soil, agricultural workers, and the cost of implementation is relatively low. Research conducted by our Russian colleagues has tested more than 70 species of pheromones and sex attractants of forest tree pests, and noted their promising role in protecting plants from pests [1].

Proof of this idea can be taken from recent studies that have been used against corn crop pests and have given relatively good biological efficacy. In this paper, experiments were conducted to determine the effectiveness of conical and aspiration pheromone traps, and it was shown that the efficiency of conical traps is higher [2].

It should also be noted that a number of scientific studies have been conducted on the application of the latest advances in science and technology in the protection of plants from pests. In particular, studies on corn pests in the Krasnodar Territory of the Russian Federation have evaluated the effectiveness of pheromone traps with LED-based luminaires and achieved significant practical results. According to the results of this experiment, it was stated that 3-4 times more pest moths were hunted and even female moths were collected in the handles on which the lamp was installed [3, 4].

In this regard, it is important from both a scientific and practical point of view to test such pheromone traps with such lighting against other types of pests. To this end, we

\footnotetext{
${ }^{*}$ Corresponding author: z.n.nosirova@yandex.com
} 
conducted field experiments on the application of adhesive pheromone handles mounted on LED-based lamps against the first mulberry moth (Glyphodes pyloalis, Walker).

The mulberry moth pest, which entered our country recently (first recorded in 1994 [5]), has caused serious damage to the silkworm network by infesting the leaves of the mulberry tree (Morus alba). We have conducted a number of scientific studies to study and apply these insect biology and control methods. In this regard, the research conducted on the classification of natural enemies of mulberry moth in the climatic conditions of Uzbekistan and their use in the protection of mulberry trees from mulberry moth [6].

Entomophagous insects such as Chrysopidae carnea [7], bracon (Bracon hebetor) [8], trichogramma (Trichogramma Evanescens Westwood) [9], and taxia (Gonia cilipera Rd.) [10] were understood in this paper. The effectiveness of the use of microbiological medicines such as "Prestige-plus" [12], chemicals such as fungi "Ashersonia" [13], "Avaunt" and "Alexander" [14] and the use of "deceptive belt" method of agro-technical measures [15], the results of research on detection can be listed.

Of course, in addition to this, research to determine the effectiveness of several microbiological medicines [16] and hormonal insecticides [17] in the activity of smoke protection against moths has also taken its place.

As a logical continuation of such research, in this article we present an analysis of the results of research to determine the effectiveness of the use of adhesive-based adhesive pheromone handles based on light-emitting diodes in the fight against mulberry moth.

Typically, pheromone traps can also be used during periods of small populations of pests. At this time they are used to prevent the emergence of pests. At a time when the number of pests is increasing year by year, it is very important to monitor the migration of this insect. More precisely, with the help of handrails it is possible to identify new areas of pest distribution, thus predicting the dynamics of its population development and calculating the distribution of insects across the affected area. In addition, such data predict the emergence and quantity of insects, at which time the optimal use of plant protection products is very important for the distribution of entomophagous.

\section{Materials and methods}

In this study, we used gauze soaked in 14-hexadecatrienyl acetate as a pheromone against mulberry moth [18].

The experiments were carried out in 5 stages in the 2019-2020 season, in June-October, on the mulberry farms of farms in Pakhtaabad district, Andijan province. The studies were conducted in 3 different variants, each with 3 repetitions. For this purpose, mulberry trees of "Uzbekistan" variety with a distance of $900 \div 1000 \mathrm{~m}$, almost identical to the mulberry moth, were selected.

The first option was to put a gauze cloth soaked in antioxidant pheromone substance mixed with water only on mulberry trees. In the second variant, the trees were covered with the same pheromone-impregnated fabric as in variant 1 , as well as a lamp based on 2 lightemitting diodes operating in the ultraviolet radiation range of $365-370 \mathrm{~nm}$. In options 1 and 2 , the pheromone was renewed once a month during the season. In option 3 , no pheromone or lamps were placed on the handles of the mulberry trees, i.e. they remained under control.

\section{Results and discussion}

Observations recorded the number of mulberry moth moths hung on the handles twice a day for 5 months, i.e. at 6 am and $8 \mathrm{pm}$. No other species of insects were caught on the handles. The results obtained by the number of captured moths are given in Table 1. 
Table 1. Number of mulberry moths caught on illuminated pheromone handles (Andijan province, Pakhtaabad district, 2019)

\begin{tabular}{|c|c|c|c|c|c|}
\hline \multirow{2}{*}{ Options } & \multirow{2}{*}{ Iteration } & \multicolumn{2}{|c|}{$\begin{array}{c}\text { Caught male } \\
\text { moths }\end{array}$} & \multicolumn{2}{|c|}{$\begin{array}{c}\begin{array}{c}\text { Caught female } \\
\text { moths }\end{array} \\
\end{array}$} \\
\hline & & Daytime & Night & $\begin{array}{c}\text { Daytim } \\
\text { e }\end{array}$ & Night \\
\hline \multicolumn{6}{|c|}{$1^{\text {st }}$ stage (From June 1 to June 30) } \\
\hline \multirow{4}{*}{1 (pheromone handle) } & 1 & 23 & 41 & 1 & 1 \\
\hline & 2 & 24 & 42 & 2 & 1 \\
\hline & 3 & 25 & 40 & - & 1 \\
\hline & Average & 24 & 41 & 1 & 1 \\
\hline \multirow{4}{*}{$\begin{array}{c}2 \text { (pheromone } \\
\text { illuminated handle) }\end{array}$} & 1 & 58 & 97 & 4 & 5 \\
\hline & 2 & 59 & 96 & 3 & 5 \\
\hline & 3 & 61 & 102 & 2 & 6 \\
\hline & Average & 59.3 & 98.3 & 3 & 5.3 \\
\hline \multirow{4}{*}{3 (control) } & 1 & 1 & 1 & - & - \\
\hline & 2 & 1 & 1 & - & - \\
\hline & 3 & 1 & 2 & - & - \\
\hline & Average & 1 & 1.3 & - & - \\
\hline \multicolumn{6}{|c|}{$2^{\text {nd }}$ stage (From July 1 to July 31) } \\
\hline \multirow{4}{*}{1 (pheromone handle) } & 1 & 16 & 21 & - & - \\
\hline & 2 & 15 & 23 & - & - \\
\hline & 3 & 16 & 25 & - & - \\
\hline & Average & 15.7 & 23 & - & - \\
\hline \multirow{4}{*}{$\begin{array}{c}2 \text { (pheromone } \\
\text { illuminated handle) }\end{array}$} & 1 & 33 & 73 & 1 & 1 \\
\hline & 2 & 34 & 75 & 1 & 1 \\
\hline & 3 & 36 & 76 & 1 & 1 \\
\hline & Average & 34.3 & 74.7 & 1 & 1 \\
\hline \multirow{4}{*}{3 (control) } & 1 & - & 1 & - & - \\
\hline & 2 & - & 1 & - & - \\
\hline & 3 & 1 & - & - & - \\
\hline & Average & 0.3 & 0.7 & - & - \\
\hline \multicolumn{6}{|c|}{$3^{\text {rd }}$ stage (From August 1 to August 31) } \\
\hline \multirow{4}{*}{1 (pheromone handle) } & 1 & 17 & 25 & - & - \\
\hline & 2 & 18 & 24 & - & - \\
\hline & 3 & 19 & 27 & - & 1 \\
\hline & Average & 18 & 25.3 & - & 0.3 \\
\hline \multirow{4}{*}{$\begin{array}{c}2 \text { (pheromone } \\
\text { illuminated handle) }\end{array}$} & 1 & 36 & 47 & 1 & 1 \\
\hline & 2 & 37 & 49 & 1 & 1 \\
\hline & 3 & 36 & 50 & - & 1 \\
\hline & Average & 36.3 & 48.7 & 0.7 & 1 \\
\hline \multirow{4}{*}{3 (control) } & 1 & - & 1 & - & - \\
\hline & 2 & - & 1 & - & - \\
\hline & 3 & 1 & 1 & - & - \\
\hline & Average & 0.3 & 1 & - & - \\
\hline \multicolumn{6}{|c|}{$4^{\text {th }}$ stage (From September 1 to September 30) } \\
\hline \multirow{4}{*}{1 (pheromone handle) } & 1 & 19 & 49 & - & - \\
\hline & 2 & 20 & 51 & - & - \\
\hline & 3 & 22 & 49 & - & - \\
\hline & Average & 20.3 & 49.7 & - & - \\
\hline \multirow{2}{*}{$\begin{array}{c}2 \text { (pheromone } \\
\text { illuminated handle) }\end{array}$} & 1 & 39 & 79 & 1 & 1 \\
\hline & 2 & 41 & 81 & 1 & 1 \\
\hline
\end{tabular}




\begin{tabular}{|c|c|c|c|c|c|}
\hline & 3 & 40 & 83 & 1 & 2 \\
\hline & Average & 40 & 81 & 1 & 1.3 \\
\hline \multirow{4}{*}{3 (control) } & 1 & - & - & - & - \\
\hline & 2 & - & - & - & - \\
\hline & 3 & - & - & - & - \\
\hline & Average & - & - & - & - \\
\hline \multicolumn{6}{|c|}{$5^{\text {th }}$ stage (From October 1 to October 30$)$} \\
\hline \multirow{4}{*}{1 (pheromone handle) } & 1 & 12 & 19 & - & - \\
\hline & 2 & 13 & 21 & - & - \\
\hline & 3 & 15 & 22 & - & - \\
\hline & Average & 13.3 & 20.7 & - & - \\
\hline \multirow{4}{*}{$\begin{array}{c}2 \text { (pheromone } \\
\text { illuminated handle) }\end{array}$} & 1 & 25 & 41 & 1 & 1 \\
\hline & 2 & 26 & 41 & - & 1 \\
\hline & 3 & 28 & 44 & - & - \\
\hline & Average & 26.3 & 42 & 0.3 & 0.7 \\
\hline \multirow{4}{*}{3 (control) } & 1 & - & - & - & - \\
\hline & 2 & - & - & - & - \\
\hline & 3 & - & - & - & - \\
\hline & Average & - & - & - & - \\
\hline
\end{tabular}

As can be seen from this table, no significant moths were trapped in the control options at all stages, as expected. Comparing the results of options 1 and 2, it appears that the number of moths hung on illuminated pheromone handles is significantly higher than on non-illuminated handles.

The highest number of searched moths was in Stage 1 (June 1 to June 30), and the lowest number of searched moths was in Stage 5. The number of moths in the remaining 3 stages corresponded to intermediate values.

The quantities of moths examined daytime and night are compared in Figure 1 for illuminated pheromone traps and in Figure 2 for illuminated pheromone traps. In this case, the stages of the experiments are described on the horizontal axis, while the quantities of moths studied on the vertical axis are described. The figure shows the number of moths observed daytime with a continuous line, with dotted lines - at night, and with dots - in the control variant.

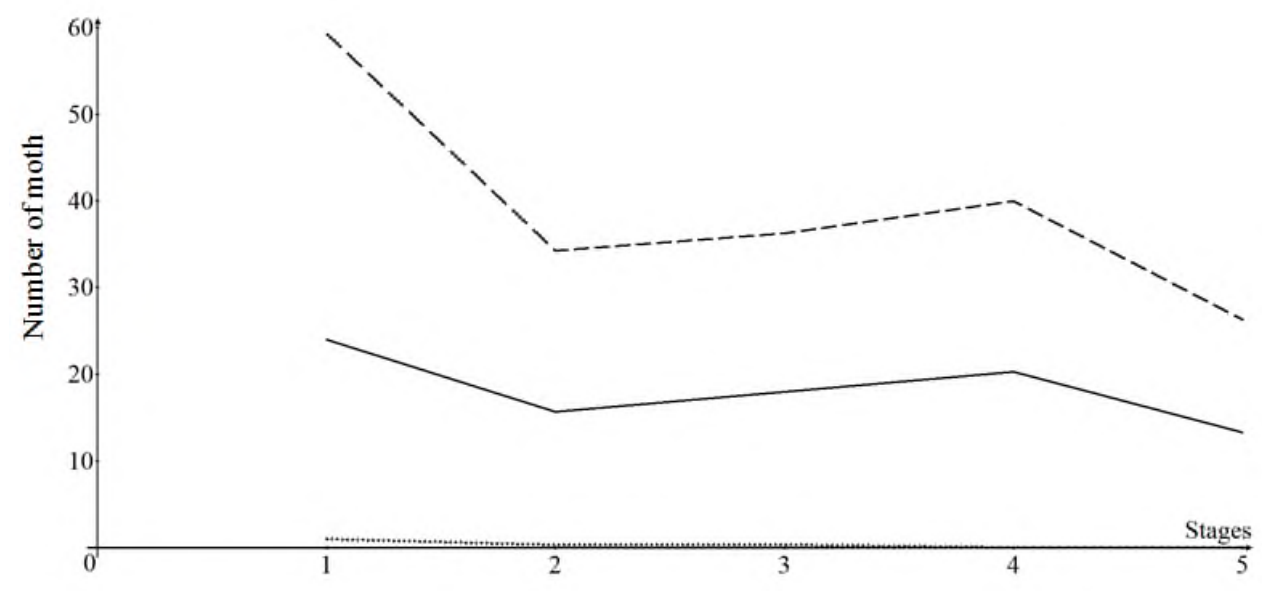

Fig. 1. Dynamics of moths on pheromone traps without illumination: solid line - daytime, contour lines - night time, and dots - control option 
It is clear from the pictures that the number of moths hunted at night is about 2 times more than the number of moth hunted daytime. The amount of moths hung on illuminated pheromone traps was almost 2 times higher than the amount of moths without light.

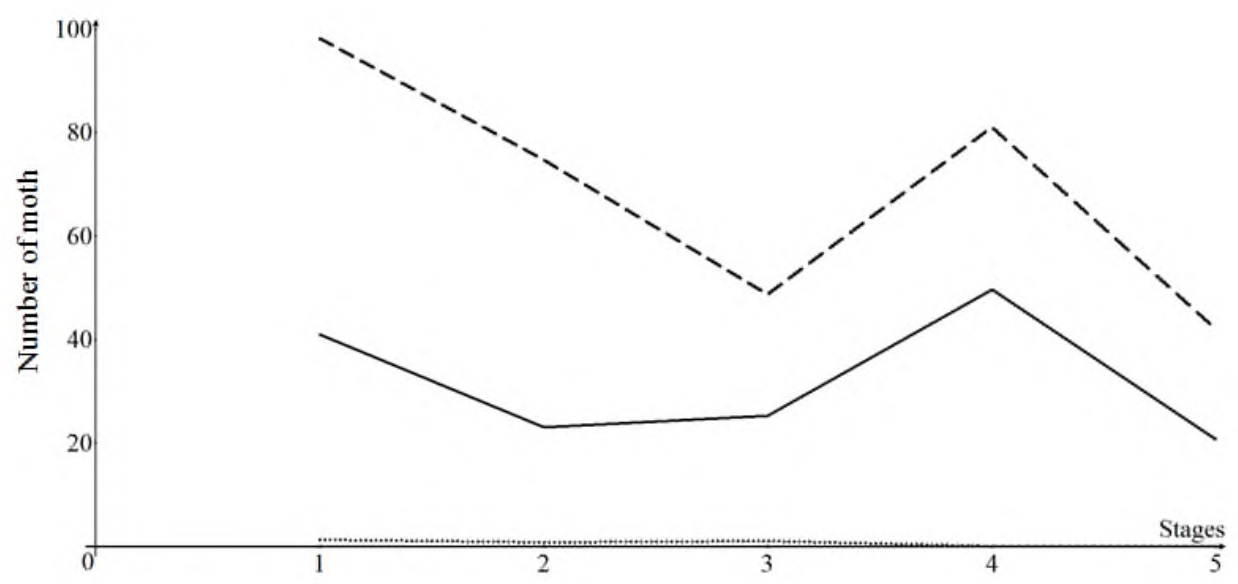

Fig. 2. Dynamics of moths on pheromone traps with illumination: solid line - daytime, contour lines - night time, and dots - control option

As for the sexual composition of the hanging moths, in contrast to the other studies mentioned above, in our study we obtained data that could be ignored in terms of the number of female moths hung on the illuminated pheromone traps [3, 4].

\section{Conclusion}

Thus, the following conclusions can be drawn from the analysis of the results of field experiments on the first application of adhesive pheromone handles against mulberry moths with LED lamps on mulberry farms of silk farms in Andijan region, Pakhtaabad district:

1. when the use of illuminated pheromone handles, 2.15 times more male moths of the mulberry moth hung than those without illuminated pheromone handles;

2. when comparing the amounts of moths examined daytime and night, it was shown that the amount of pest examined during the night was 1.75 times higher;

3. in our 5-month follow-up experiments, no significant results were obtained on the number of female moths examined for control options.

This means that the application of the latest advances in science and technology for plant protection, in particular the use of LED-based light pheromone traps in the fight against mulberry moth, has yielded good results in pest control activities.

\section{References}

1. K. V. Lebedeva, N. V. Vendilo, V. A. Pletnev, Agrochemistry 8, 77-89 (2012)

2. R. Zelenskiy, A. Kurilov, O. Kremneva, V. Sadkovskiy, In: the tenth All-Russian Conference of Young Scientists and Specialists, 66-69 (2019)

3. A. Frorov, I. Grushevaya, A. Kononchuk, S. Malysh, A. Miltsin, In: Fifth International Conference "Conceptual and applied aspects of scientific research and education in the field of invertebrate zoology", 164-167 (2020) 
4. I. Grushevaya, A. Kononchuk, S. Malysh, A. Miltsin, A. Frorov, Bulletin of Plant Protection 4(102), 49-54 (2019)

5. M. Shermatov, M. Akhmedov, Biological Journal of Uzbekistan 4, 53-57 (2002)

6. Z. G. Nosirova, Agrarian Russia 8, 42-48 (2020)

7. KH. Kimsanboev, Z. Nosirova, Agrarian Russia 7, 4-6 (2017)

8. Z. Nosirova, KH. Kimsanboev, European Applied Sciences 3, 3-5 (2017)

9. Z. Nosirova, KH. Ergasheva, Michurinsky agronomic bulletin 2, 7-12 (2019)

10. Z. Nosirova, Bulletin of Altai State Agrarian University 2(160), 70-74 (2018)

11. KH. Kimsanboev, Z. Nosirova, Plant Protection and Quarantine 5, 45-46 (2018)

12. KH. Ergasheva, Z. Nosirova, Eurasian Union of Scientists 5(52), 46-51 (2019)

13. S. Ubaydullaev, Z. Nosirova, D. Ruzikulov, International journal of scientific \& technology research 8(11), 1408-1410 (2019)

14. J. Rakhmonov, Z. Nosirova, M. Rustamova, Agrochemical protection and plant quarantine 3(7), 50-51 (2018)

15. M. Tadjieva, Z. Nosirova, KH. Ergasheva, Soild State Technology 63(4), 336-443 (2020)

16. Z. Nosirova, KH. Ergasheva, The American Journal of Agriculture and Biomedical Engineering 10, 1-6 (2020)

17. K. Y. Seol, H. Honda, Y. Matsumoto, Applied Entomology and Zoology 21(2), 228235 (1986)

18. T. Ando, Y. Ogura, M. Koyama, M. Kurane, M. Uchiyama, K. Seol, Agricultural and Biological Chemistry 52(10), 2459-2468 (1988) 